\title{
Affect or information? Examining drivers of public preferences of future energy portfolios in Switzerland
}

\author{
Journal Article \\ Author(s): \\ Jobin, Marilou; Visschers, Vivianne H.M.; van Vliet, Oscar P.R.; Arvai, Joseph; Siegrist, Michael \\ Publication date: \\ 2019-06 \\ Permanent link: \\ https://doi.org/10.3929/ethz-b-000331047
}

Rights / license:

Creative Commons Attribution-NonCommercial-NoDerivatives 4.0 International

Originally published in:

Energy Research \& Social Science 52, https://doi.org/10.1016/j.erss.2019.01.016 


\title{
Affect or information? Examining drivers of public preferences of future energy portfolios in Switzerland
}

Marilou Jobin $^{\mathrm{a}, \star}$, Vivianne H.M. Visschers ${ }^{\mathrm{b}}$, Oscar P.R. van Vliet ${ }^{\mathrm{c}}$, Joseph Árvaid ${ }^{\mathrm{de}}$, Michael Siegrist ${ }^{\mathrm{a}}$

${ }^{a}$ ETH Zurich, Institute for Environmental Decisions (IED), Consumer Behavior, Zurich, Switzerland

${ }^{\mathrm{b}}$ University of Applied Sciences and Arts Northwestern Switzerland, School of Applied Psychology, Olten, Switzerland

${ }^{c}$ ETH Zurich, Institute for Environmental Decisions (IED), Climate Policy, Zurich, Switzerland

${ }^{d}$ School for Environment and Sustainability, Stephen M. Ross School of Business, and Erb Institute for Global Sustainable Enterprise, University of Michigan, Ann Arbor, MI, USA

${ }^{\mathrm{e}}$ Decision Research, Eugene, OR, USA

\begin{abstract}
The energy transition in Switzerland, as in many other countries, aims to increase the proportion of electricity produced using renewable energy technologies. In this context, governmental agencies and other institutions have attempted to communicate the implications of (domestic) electricity systems through the use of web-based and interactive decision support systems (DSSs). Studies show that, when no additional information is provided, preferences concerning the future electricity mix are mainly driven by the affective reactions that energy technologies evoke. A question remains, however, regarding how people engage with the information provided in a DSS, as well as whether such information is influential in terms of shaping people's choices. We asked our participants to build an electricity portfolio using a DSS, which modeled the Swiss electricity system. The participants' political orientation and their affective reactions to different energy technologies guided their information search, as well as the choice of energy technologies within their portfolio. The attention paid to the information provided was not directly related to the participants' portfolio choices. The selective processing of information, which was based on the participants' prior attitudes, suggests that they target information they are already familiar with in the DSS. However, this also illustrates a caveat previously identified in motivated political reasoning, since selective information processing, together with the tendency to disconfirm information that is incongruent with prior beliefs, can lead to the polarization of previously held views. As the information provided through the DSS we tested was unable to change the participants' affective-cognitive evaluation of energy technologies, its use should be carefully considered in light of the possible effects of consolidating existing beliefs.
\end{abstract}

\section{Keywords}

Decision support system, information search, affect, energy portfolio preferences, electricity mix

(C) 2018. This manuscript version is made available under the CC-BY-NC-ND 4.0 license http://creativecommons.org/licenses/by-nc-nd/4.0/ https://doi.org/10.1016/j.erss.2019.01.016

Accepted 18 January 2019

*corresponding author, E-mail address: marilou.jobin@ hest.ethz.ch, phone number: +41 446338316 


\section{Introduction}

Energy transitions intended to achieve more sustainable and secure energy systems are currently underway in various countries worldwide. The aim of such transitions is to counter the persistent andin the minds of many-unsustainable investments made in fossil-fuel-based energy sources (Stern, Sovacool, \& Dietz, 2016), as well as to achieve the decrease in the primary energy demand projected by the International Energy Agency (IEA, 2017). In the case of Switzerland, the country's planned energy transition is based on three pillars: the phasing out of existing nuclear power plants, the expansion of renewable energies, and increased energy efficiency (Swiss Federal Office of Energy [SFOE], 2013a). A new Energy Act was enacted in Switzerland in 2018 that, amongst other changes, modified the feed-in tariffs for new renewable electricity technologies so as to incentivize further investment in such technologies (SFOE, 2017).

Though the Swiss public does not exhibit uniform preferences with regard to the expansion of renewables domestically, a main difference appears to be in terms of how best to combine domestic renewable power production - with either renewable imports or non-renewable technologies (Jobin \& Siegrist, 2018). In this study, the demonstrated portfolio preferences were mainly driven by the participants' affective responses, that is, the feelings evoked by energy technologies. In general, the more positive people's feelings about a given energy technology are, the more likely they are to include that technology in their portfolio (Jobin \& Siegrist, 2018). Yet, appeals have been made that energy consumers, among others, should be more informed about their energy-related choices and rely on facts rather than opinions (Stern et al., 2016). In pursuit of this goal, communicating facts to the public on the consequences of the energy transition has been attempted in Switzerland, with the help of an online interactive tool. ${ }^{2}$ Furthermore, previous research investigated decision support systems (DSS) in terms of public engagement on the national level (Pidgeon, Demski, Butler, Parkhill, \& Spence, 2014), usability of such tools (Mayer, Bruine de Bruin, \& Morgan, 2014), and decision outcomes in relation to what people value(Bessette, Arvai, \& Campbell-Arvai, 2014; Bessette, Campbell-Arvai, \& Arvai,

\footnotetext{
${ }^{2}$ Energyscope, allows comparing different scenarios of the Swiss energy strategy, showing different possible pathways. http://www.energyscope.ch/ [Accessed April 11, 2018].
} 
2016). However, with few exceptions (Arvai \& Gregory, 2003; Bessette et al., 2014; Bessette et al., 2016), how the public engages with interactive tools has to be fully explored.

The objective of this research is therefore to examine how, in addition to affective evaluations, information processed in an interactive DSS may influence the Swiss public's portfolio choices. As the main concern of the energy transition is to increase renewable electricity production generally (SFOE, 2013b) and major differences between public preferences stem from different views on how to combine domestic renewable electricity production (Jobin \& Siegrist, 2018), the present research focuses on the drivers of the proportions of renewable energy technologies the public included in a portfolio altogether.

\subsection{Affect}

Previous research found that feelings and emotions are relevant in explaining people's support for energy technologies (Truelove, 2012; Visschers \& Siegrist, 2014), being the central explanatory factor compared to e.g. risk or benefit perception (Visschers, Keller, \& Siegrist, 2011). The importance of affect held true when people chose their preferred energy technology portfolio instead of indicating their level of acceptance or support (Jobin \& Siegrist, 2018). Further evidence can be found that affective reactions guide people's evaluation of information and, ultimately, influence their acceptance of a technology. The affective impressions carbon capture and storage (CCS) technology evoked before and after reading educational material were strongly related, suggesting that information did not change initial feelings about the technology (Bruine de Bruin \& Wong-Parodi, 2014). Wilson and Arvai (2006) found empirical evidence that the affective characteristics of a given problem were more relevant to people's willingness to pay in order to counter a natural management problem, when compared to the quantitative information provided about the risks stemming from that problem. In other words, people preferred to attribute more money to risk reduction for an "affect-rich but lower risk problem" when it could be evaluated jointly against an "affect-poor but (slightly) higher risk problem" (Wilson \& Arvai, 2006, p. 174). When objective quantitative information is provided, people's affective processes can overrule the aspects of the decision-making process that require more thoughtful deliberations. Finally, in a prior study concerning the use of a decision support system (DSS) for energy, there were indications that people were influenced by the types of technologies, provided the names of technologies were 
shown, rather than by the consequences the portfolio had. If the names were provided, they tended to avoid energy portfolios that included nuclear power, potentially due to negative affective reactions with nuclear. This effect was not found for natural gas or coal with carbon capture and storage (Bessette et al., 2016).

\subsection{Information}

It is not only affective reactions that are relevant to acceptance, since the attributes of different sources of electricity production have also been found to be relevant in this regard. For instance, both the price of electricity and the impacts on the local environment that pose risks to human health, such as air pollution (Ansolabehere \& Konisky, 2014; Stokes \& Warshaw, 2017), have been found to be important. Information that suggested a higher price of electricity generated by renewable technologies was related to a lower preference for renewable technologies (Ansolabehere \& Konisky, 2014), and decreased acceptance of renewable energy legislation (Stokes \& Warshaw, 2017). Low prices might however not always be the most important attribute for energy technology preferences. Under circumstances where people could construct their own energy technology portfolios, both the reduction of greenhouse gases and air particulate emissions were a priority, even if this implied high costs (Bessette \& Arvai, 2018). Previous research already showed that people consider nuclear power plant's contribution to mitigating $\mathrm{CO}_{2}$ emissions when determining their acceptance (Corner et al., 2011; Visschers et al., 2011). Information about the negative consequences of power plants has been found to decrease people's level of acceptance, even when such technologies had initially triggered very positive affective associations (Sütterlin \& Siegrist, 2017). For example, the study investigated people's level of acceptance after they were provided with information about the generation of toxic waste during the production of solar panels. The same effect was found for the negative consequences associated with hydropower (i.e., negative impacts on the landscape, flora, and fauna) and wind power (i.e., negative impacts on the landscape and bird life) (Sütterlin \& Siegrist, 2017). Information concerning other attributes can also be relevant. People consider by whom power plants are owned (Tabi \& Wüstenhagen, 2017), as well as negative effects on wildlife (Bergmann, Hanley, \& Wright, 2006), biodiversity and landscapes (Tabi \& Wüstenhagen, 2017). 


\subsection{The decision support system}

In the above-mentioned studies, information was provided in different ways, ranging from the evaluation of one energy technology based on one attribute (Sütterlin \& Siegrist, 2017; Tabi \& Wüstenhagen, 2017), to comparative evaluations of multiple energy technologies based on one attribute (Ansolabehere \& Konisky, 2014), to comparative evaluations of multiple alternatives (i.e., different energy legislation) based on multiple attributes (Stokes \& Warshaw, 2017). How the information and alternatives are presented clearly matters. According to Hsee (1996), in situations where alternatives are compared jointly, the comparison helps to contextualize the information, while in individual evaluation settings, the information is predominantly considered by the intuitive-affective system. Both types of evaluations result in different preferences.

In order to provide information about energy technologies in the present study, we make use of an interactive DSS. Such systems can be used to deliver information that can be processed comparatively across different alternatives. They also provide information regarding the choices (e.g., of energy technologies), and they deliver feedback to users on the consequences of their choices (Bessette et al., 2016). The basic premise behind a given DSS is that it may assist decision makers in making complex choices, and it may further help to communicate information in a way that decision makers understand (Zikmund-Fisher, Dickson, \& Witteman, 2011). When designed in such a way to decompose complex decisions into more manageable steps, these systems may also lead to different choices that are more consistent with people's goals (Bansback, Li, Lynd, \& Bryan, 2014; Bessette et al., 2014; Bessette et al., 2016; Mayer et al., 2014).

DSSs have been applied for various purposes in the past, for example, to aid in assessing the side effects of medical treatment (Bansback et al., 2014), for land use management (Arvai \& Gregory, 2003; Arvai, Kellon, León, Gregory, \& Richardson, 2014), and to help people design and choose energy portfolios (Bessette et al., 2014; Bessette et al., 2016; Mayer et al., 2014; Pidgeon et al., 2014). In order to help provide a rigorous basis for a decision-making process, DSSs display real-world constraints, thereby portraying the issue in realistic terms (Bessette et al., 2014). 


\subsection{Study aims and set-up}

The present study focuses on how people engage with a DSS that provides information via an interactive interface. We were interested in whether participants' search for information, or whether their reliance on affective evaluations of energy technologies is more strongly related to the type of electricity portfolio they choose. As we focused on the proportions of renewable energy technologies that the participants included in their portfolios, our question was, whether affect or processed information is the stronger predictor of the proportion of renewable energy in portfolios.

In accordance with the above-mentioned research, we expected to find a stronger relation between affect and the proportion of renewable energy compared to the relation between processed information and the proportion of renewable energy. Hence, more precisely, we examined the extent to which affect and the information search concerning renewable energy technologies (RE) and non-renewable energy technologies (NRE) predicted the proportion of renewables within the participants' electricity portfolios. In a more exploratory effort, we were also interested in how much attention participants paid to information on RE and NRE technologies and what factors predict information search in an interactive DSS.

To that end, we developed a DSS that models the Swiss electricity system (see also section 2.2.1). The design of the DSS focused on providing information that could be accessed voluntarily using an interactive interface. The users of the DSS were asked to develop a portfolio of different energy technologies in order to generate sufficient electricity to meet domestic demand. This latter point represents both a real-world constraint and a requirement that the users needed to fulfil. The DSS also provided direct feedback on how well the chosen portfolio performed with regard to the demand requirements (as was the case in Bessette et al., 2014; Bessette et al., 2016; Mayer et al., 2014; Pidgeon et al., 2014). Further, the DSS allowed users to access different types of information concerning each technology, as well as interactive feedback regarding the impacts of their entire portfolio. ${ }^{3}$

\footnotetext{
${ }^{3}$ The interactive feedback did not form part of the current analysis. In the following, we concentrate on the attention participants paid to information concerning individual energy technologies.
} 


\section{Methods}

\subsection{Procedure}

The data for this study were collected between October 9 and November 10, 2017. Announcements placed in two local online and print city newsletters, as well as on notice boards in supermarkets, were used to recruit participants. The announcements described the context of the study as "decisions concerning electricity", and they stated the requirement that participants' primary language must be German. The study was conducted in a computer room at our institute. Computers with Internet access were used to present the web-based DSS and the questionnaire (programmed using Unipark software [Questback Ltd], 2015). The participants performed the tasks individually, and they were separated from each other using dividing walls in order to ensure this. On average, ten persons participated simultaneously. After they had finished all the tasks, the participants were thanked, debriefed regarding the purpose of the study, and remunerated with 30 Swiss francs for taking part in the study.

\subsection{Materials}

\subsubsection{The DSS}

We developed a web-based DSS that represents a simplified model of the Swiss electricity system, which was presented to the participants via an interactive online user interface. The DSS was developed in collaboration with a web developer (https://ied-dss.ethz.ch) specifically for the purpose of the present study. The elements of the model that were to be presented and the interface of the DSS were each determined using the first two steps of the mental model approach, which was initially used to develop and test communication materials concerning technologies and risks (Morgan, Fischhoff, Bostrom, \& Atman, 2002). As a first step, we conducted semi-structured interviews with fifteen experts so as to elicit an expert model of the Swiss electricity system, as well as to identify what the public should know about it. The interviewed experts were selected based on two criteria: (i) their work was related to energy issues, and (ii) they were familiar with different energy technologies (Blumer, Moser, Patt, \& Seidl, 2015). In order to include different views regarding the Swiss energy transition (Markard, Suter, \& Ingold, 2016), we chose to interview experts with different affiliations (including affiliations with 
government bodies at the federal and cantonal levels, academia, industry, and non-governmental organizations [NGOs]). Based on the interviews, we determined the relevant dimensions that should be represented in the DSS, for example, that the chosen portfolio should satisfy the yearly domestic energy demand and, further, that the choice of energy technologies should be limited based on their technical potentials in Switzerland, which should reflect a more realistic choice situation (see Table 1). We also actioned the suggestion that we show the impact of a chosen portfolio on, for example, land use or the environment.

As a second step, we conducted eight semi-structured interviews with laypeople in order to determine what the public actually knows with regard to the Swiss electricity system, as well as what they are especially interested in. The participants were selected using the "maximum variation method" suggested by Seidman (1998), which involves choosing persons who differ with respect to gender, age, and education. Through the interviews, we gained knowledge about the concepts and terms that laypeople are familiar with, their knowledge gaps and misconceptions, and therefore, the type of information laypeople might need to make an informed decision. This second step was relevant in terms of ascertaining that the material included in the DSS would be meaningful to, and understood by, the general public (Howarth, 2017). We found that the laypeople asked questions related to the spectrum of existing technologies ("What type of technologies actually exist?"), thereby confirming the need to provide an overview of the available choice options for producing electricity. They also enquired about the impacts of both electricity production ("How expensive will electricity be?") and different technologies ("Do power plants produce waste?"), which highlighted the need to show the consequences of a given energy technology portfolio.

In the DSS, the participants were instructed to combine their preferred energy portfolio for the year $2035^{4}$ (see Text Box 1), and they received instructions on how to do so (see Text Box 2). The DSS allowed the construction of a portfolio based on eight different energy sources: 1) hydropower, 2) solar

4 The year 2035 is a milestone in the Swiss electricity transition, which has set target values for the amount of renewable energy technologies to be included in the Swiss electricity mix. 
power, 3) wind power, 4) power derived from biomass and waste incinerators, 5) natural gas power, 6) new nuclear power, 7) imported renewable electricity, and 8) imported non-renewable electricity.

As they developed their preferred portfolios, the participants were able to look up information regarding 1) the current installed capacity, 2) the climate impact, 3) the health impact, 4) waste, 5) conflicted land use, and 6) the costs of each type of energy technology (see Figure 1, matrix in the middle field). Further, as an added feature of the DSS, the participants could look up the aggregate effects of their overall portfolio. This "feedback information" was accessible at any time during the task, and it covered the same topics that were separately shown for each energy technology in the matrix. These topics were: 1) the generated $\mathrm{CO}_{2}$ emissions, 2) the price of the electricity produced, 3) the waste produced, 4) the percentage of plants for which land use could be conflicted, and 5) the health impact (see Figure 1, blue buttons in the upper right corner). At any time during the task, the participants were able to simultaneously open a maximum of two types of information, choosing from either the matrix or the feedback information.

Text Box 1. Instructions for the portfolio choice in the DSS

\section{Welcome to the electricity-portfolio builder}

Imagine you can define how Switzerland will produce electricity in 2035, according to your preferences.

Your task on the next page is to choose an electricity portfolio that covers at least $100 \%$ of the electricity demand in Switzerland for the year 2035.

The following information is important:

- You need to produce enough electricity with your chosen portfolio to cover demand for a typical winter day when we need the most electricity. You thereby assure that there will be enough power plants to cover demand all year round.

- Your choice is limited, as you cannot dismantle existing infrastructure.

- For every technology, you can at most choose the maximal technical potential for Switzerland.

- The impacts of your electricity portfolio will be shown for the whole year. 
Text Box 2. Instructions on navigating the DSS

\section{Please consider the following instructions for navigating the application:}

- In the upper left corner, you see how much electricity your portfolio produces on a winter day. The amount of electricity shown when opening the DSS is the amount that is currently produced by the already installed infrastructure. The dotted line shows how much you still need to produce, that is, 193.5 gigawatt hours per day.

- Information on the individual technologies is accessible by clicking on the matrix table in the middle of the page.

- Information on the impacts of the portfolio can be viewed by clicking the blue buttons on the right side of the page.

- You can only compare two different types of information at the same time. By closing them, you get back to the main page or you create new space for other information.

- You can mouse over parts of the graphs or difficult words to get more detailed information.

- You can submit your chosen portfolio when you are satisfied with your choice and the submit button is red.

Please take enough time to choose your preferred portfolio.

The participant's choices in the DSS were limited by two constraints. First, their portfolio had to fulfil the electricity demand for a typical winter day. We chose a winter day because hydropower and solar power exhibit their lowest production capacities at that time of year, and we hence ensured that sufficient power plants would be built to cover the demand over the whole year. This meant that the participants could only submit their portfolio if it covered the electricity demand (as indicated by a dashed line in the electricity production graph in Figure 1); otherwise, the submit button remained inactive. Second, the DSS limited the number of power plants that could be chosen for each energy technology to its respective technical potential in Switzerland. More specifically, it was not possible to choose less than the current installed capacity of each energy technology, with the exception of new nuclear power ${ }^{5}$ (because the Swiss government plans to phase out the existing nuclear power plants), or more than the maximum technical potential of that technology in Switzerland (i.e., maximum

\footnotetext{
${ }^{5}$ Even though new nuclear power plants cannot currently be built in Switzerland due to the new Energy Act (SFOE, 2017), it would theoretically be possible to overturn this law in the future. As the new Energy Act is not a constitutional law, a change to this law requires only a majority vote in the Council of States and the National Assembly, who together constitute the Swiss parliament. The public, however, could take up a facultative referendum during the 100-day period following a parliamentary decision, which would require a subsequent national vote on the issue. Therefore, we included new nuclear power in the DSS.
} 
potential). For example, the participants could choose between $9.14 \mathrm{GW}$ and $9.6 \mathrm{GW}$ of hydropower in their portfolio. This range is based on the current installed capacity $(9.14 \mathrm{GW})$ and the projected potential for growth $(9.6 \mathrm{GW})$ for this specific technology, as based on the maximum number of additional hydro facilities that could conceivably be deployed in Switzerland (SFOE, 2012). The minimum and maximum capacities for the energy technologies were implemented in the DSS in the form of slide bars that were limited by the minimum infrastructure that had to be chosen on the left and by the maximum potential on the right. Next to the slide bars, both the number of plants and the installed capacities (in gigawatts) were indicated (see Figure 1). An overview of the minimum and maximum capacities of each energy technology is presented in Table 1.

Table 1

Minimum and maximum capacities of each energy technology as set in the DSS

\begin{tabular}{|c|c|c|c|}
\hline Energy technology & $\begin{array}{l}\text { Minimum estimated } \\
\text { capacity [GW] }\end{array}$ & $\begin{array}{l}\text { Maximum estimated } \\
\text { capacity [GW] }\end{array}$ & Sources \\
\hline Solar panels (on rooftops) & 1.39 & 13.6 & $\begin{array}{l}\text { (Assouline, Mohajeri, \& } \\
\text { Scartezzini, 2017; SFOE, } \\
\text { 2016) }\end{array}$ \\
\hline Wind power & 0.06 & 11.3 & $\begin{array}{l}\text { (Kienast et al., 2017; } \\
\text { SFOE, 2016) }\end{array}$ \\
\hline Biomass and waste incinerators & 0.42 & 2.3 & $\begin{array}{l}\text { (Panos \& Kannan, 2016; } \\
\text { SFOE, 2016)( }\end{array}$ \\
\hline Hydropower & 9.14 & 9.6 & (SFOE, 2012, 2016) \\
\hline Natural gas power & 0.25 & 4.25 & $\begin{array}{l}\text { (SFOE, 2016), Maximum } \\
\text { defined* }\end{array}$ \\
\hline New nuclear power & 0.00 & 4.0 & Maximum defined* \\
\hline Imported renewable electricity & 0.00 & 4.2 & Maximum defined* \\
\hline Imported non-renewable electricity & 0.00 & 3.8 & Maximum defined* \\
\hline
\end{tabular}

Note. *The maximum was defined so that the Swiss electricity demand could be covered with the choice of either natural gas, new nuclear power, or imported renewable or non-renewable electricity, in addition to the minimum capacities for solar panels, hydropower, natural gas power, biomass and waste incineration, and wind power. 

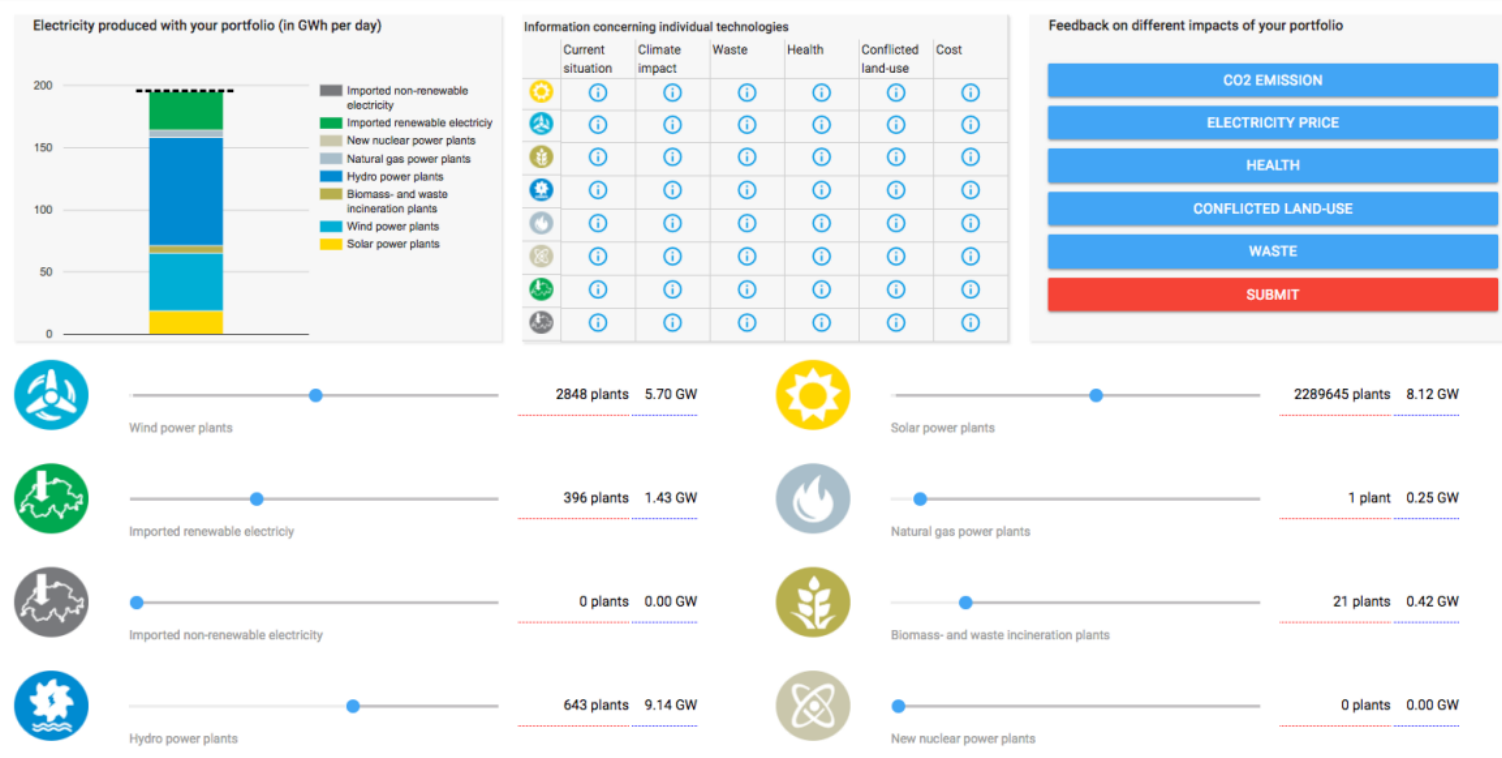

Figure 1. The main interface of the DSS, showing a completed portfolio.

\subsubsection{Measures}

\subsubsection{Affect}

The questionnaire began by measuring the participants' evoked affect for each energy technology that was later presented in the DSS. The participants were asked "What kind of feelings are being evoked in you when thinking about the following technologies?" The participants indicated their affect for each energy technology on a scale ranging from 0 "very negative feelings" to 100 "very positive feelings", on which the midpoint, 50, was labelled "neither positive nor negative" (Lienert, Sütterlin, \& Siegrist, 2017). We computed the mean of the affect scores for all five renewable technologies in order to generate an overall measure of the affect experienced with regard to renewable energy technologies (affect RE), as well as the mean of the affect score for the three non-renewable technologies so as to generate an overall measure of the affect experienced with regard to non-renewable technologies (affect NRE).

\subsubsection{Socio-demographic variables}

A number of socio-demographic variables, namely gender, age, education, and political orientation, concerning the participants were also collected. We measured the participants' political orientation on 
a left-right self-placement scale ranging from 1 "completely left" to 10 "completely right" (Breyer, 2015; Rudolf, Seidl, Moser, Krütli, \& Stauffacher, 2014).

\subsubsection{Portfolio choice}

The participants' chosen portfolios were logged. For every energy technology, the installed capacity was recorded in gigawatts $(\mathrm{GW})$, while we computed the electricity produced by each technology in gigawatt hours $(\mathrm{GWh})$. Based on the total electricity a given participant had selected, we calculated the proportion of every energy technology in that participant's portfolio. The main goal of the energy transition in Switzerland is to substitute part of the non-renewable electricity production through renewable energy technologies (SFOE, 2013b). For further analyses, we therefore computed the proportion of all five renewable energy technologies as the sum of the proportions of hydro, solar, wind, biomass and waste, and imported renewable electricity (proportion RE). The proportion of all the nonrenewable energy technologies was calculated as the sum of the proportions of nuclear, natural gas, and imported non-renewable electricity (proportion NRE). Taken together, the proportions of RE and NRE constitute $100 \%$ of the portfolio.

\subsubsection{Attention to information}

Within the DSS, process tracing by means of Mouselab was used to collect data (Schulte-Mecklenbeck, Kühberger, \& Ranyard, 2011). We chose this measure as we were emulating a normal website and Mouselab helps to ensure that data collection is not actively experienced by participants. Prior studies have used Mouselab to track participants' information processing, for example, in the food choice domain (Schulte-Mecklenbeck, Kühberger, Gagl, \& Hutzler, 2017; van Buul, Bolman, Brouns, \& Lechner, 2017).

Mouselab tracked how frequently the participants accessed information about each technology. To account for the fact that not all participants accessed information equally often, we normalized each participant's frequency of attending to information concerning one technology to the total amount of information they retrieved. This indicated the attention participants gave to a type of energy technology. As there were unequal numbers of renewable (five technologies) and non-renewable technologies (three technologies) from which participants could gather information, we then averaged the scores across a) 
all renewable technologies (average \% information RE) and b) all non-renewable technologies (average $\%$ information NRE). The scores indicated the attention a person paid to information to renewables on average and the attention they paid to information on non-renewables on average.

\subsection{Participants}

In order to ensure that the sample included equal representation of men and women, as well as a similar distribution of education levels, as seen within the general Swiss population, we employed quota sampling during participant recruitment. The quota for the different education levels was primary schooling (12.6\%), secondary education (46.2\%), and tertiary education $(41.3 \%)$ as the highest achieved education level. The quota for age consisted of five fairly equally distributed age groups between 18 and 70 years. The quotas were based on census data obtained from the Swiss Federal Statistical Office (FSO, 2017a, 2017b).

A total of 100 people took part in this study. Participants were eliminated from the sample if they chose an excessive amount of energy (more than $222 \mathrm{GWh}$, corresponding to more than a $15 \%$ deviation from the target of $193.5 \mathrm{GWh}){ }^{6}$ Further, we eliminated those participants who took less than half the median time (24.2 minutes) to complete all the study tasks. The final sample comprised 85 participants (57.6\% female). The average age was 41.6 years $(\mathrm{SD}=13.5)$, ranging from 19 to 71 years. Approximately $6 \%$ of participants had completed primary education, $39 \%$ secondary education, and $55 \%$ tertiary education. The sample was slightly better educated when compared to the general Swiss population (FSO, 2017a). Further, the age group 18-29 years was somewhat overrepresented in the sample, while the age group 60-70 years was somewhat underrepresented (FSO, 2017b).

\footnotetext{
${ }^{6}$ The maximum amount of energy people could choose was not limited to $193.5 \mathrm{GWh}$ exactly. This was the case as choosing, for example, an additional gas power plant would lead to a larger increase in the electricity produced when compared to one additional wind power plant. However, looking at the distribution of the values for the total amount of energy produced in the chosen portfolios, a stem and leaf diagram revealed that values above 222 GWh represented extreme cases. Based on this, 11 participants were deleted from the analysis.
} 


\section{Results}

\subsection{Portfolio choice}

The average electricity portfolio included all the presented energy technologies, as can be seen in Figure

2. However, a closer look at the proportions of the different energy technologies in the portfolio showed that the sizes of their variations differed between energy technologies. The chosen amount of energy varied strongly for wind power, with 50\% of participants choosing an amount between $19.23 \mathrm{GWh}$ and 54.48 GWh, while they varied to a lesser degree for natural gas and imported renewable electricity, which had similar limits to energy production. In contrast, the majority of participants did not include any new nuclear power or non-renewable electricity imports (Figure 2).

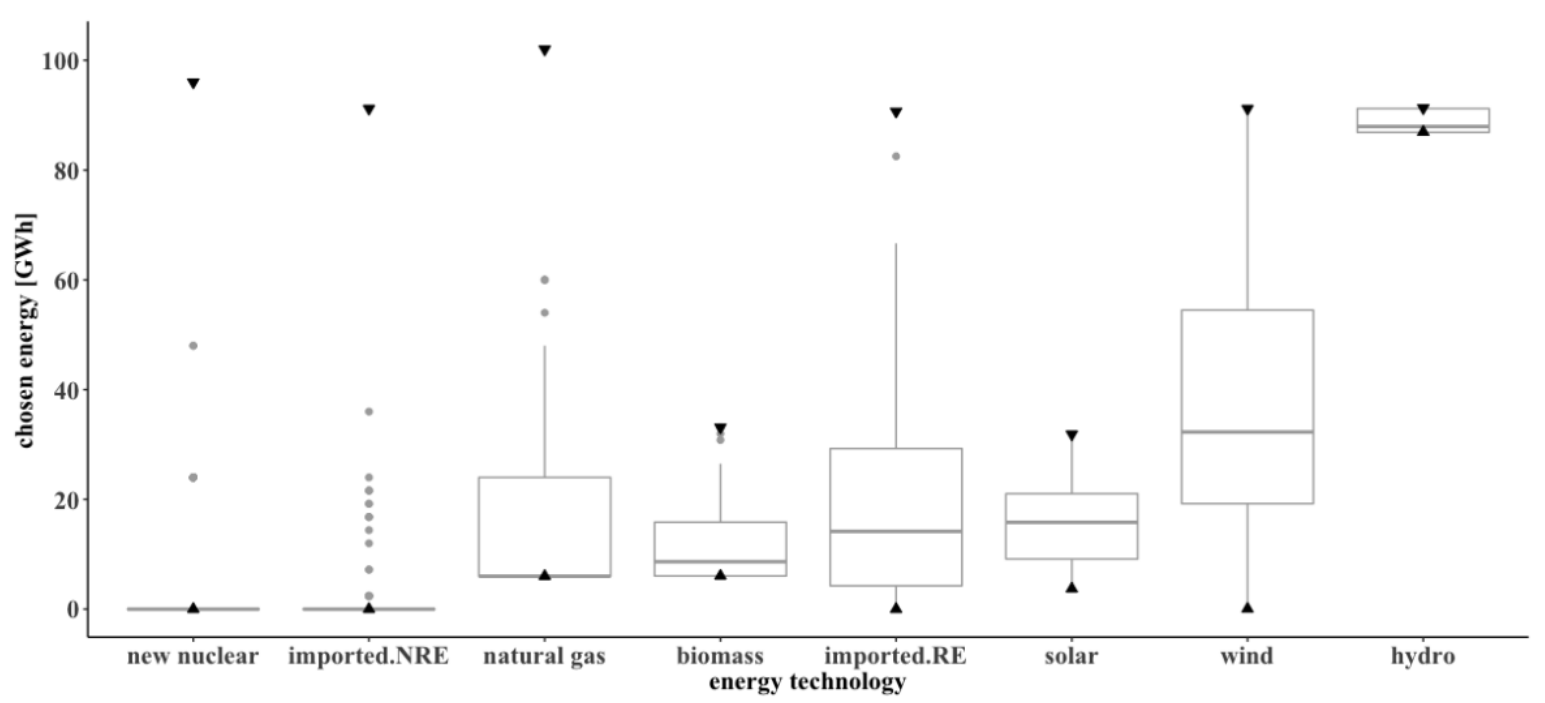

Figure 2. Distributions of the chosen amount of energy [GWh] per energy technology in the portfolios $(\mathrm{N}=85)$, including the respective median (thick line) and the lower and upper quartiles (boxes) in the table. The abbreviations stand for hydropower (hydro), solar panels (solar), wind power (wind), biomass and waste incineration (biomass), imported renewable electricity (imported.RE), natural gas power (natural gas), new nuclear power (new nuclear), and imported non-renewable electricity (imported.NRE). $\boldsymbol{\Delta}$ shows the minimum estimated energy [GWh] and $\boldsymbol{\nabla}$ shows the maximum estimated energy [GWh], based on the estimated minimum and maximum capacities shown in Table 1.

\subsection{Relationships between political orientation, affect, and information search}

We computed the Pearson's correlations for all the investigated variables in order to examine their bivariate relationships (Table 2). Political orientation correlated significantly negatively with the affect experienced regarding RE. That is, the more a person was oriented toward the right on the political scale, the more negative their affect toward renewable technologies was. The reverse was also true, 
meaning that a more left-leaning political orientation was positively correlated with affect toward RE. According to the same pattern, political orientation was also negatively correlated with the proportion of RE, as well as positively correlated with the proportion of NRE, in the portfolio.

The degree to which information was attended to, on average, for RE correlated significantly positively with the affect toward RE and the affect toward NRE. Hence, more positive affective reactions toward renewables, but also toward non-renewables, were related to more information being attended to with regard to RE technologies. In addition, age was negatively correlated with information being attended to regarding RE. These relationships were, however, not significant for the amount of attention paid to information about NRE technologies. Yet, the percentage of information concerning NRE was related to participants' political orientation. Being oriented more toward the right was related to attending to less information about NRE technologies (see Table 2).

It is important to note that the participants' average attention to information about RE technologies was significantly higher $(M=0.12, S E=.01)$ when compared their average attention to information about NRE technologies $(M=.06, S E=.01)$, as demonstrated by the conducted pairwise t-test $(t[84]=6.23$, $p=.0005)$.

Table 2

Pearson's correlations between the investigated variables

\begin{tabular}{|c|c|c|c|c|c|c|c|c|c|}
\hline & Education & $\begin{array}{r}\text { Political } \\
\text { orient. }\end{array}$ & Age & $\begin{array}{r}\text { Affect } \\
\text { RE }\end{array}$ & $\begin{array}{l}\text { Affect } \\
\text { NRE }\end{array}$ & $\begin{array}{r}\text { Proportion } \\
\text { RE }\end{array}$ & $\begin{array}{r}\text { Proportion } \\
\text { NRE }\end{array}$ & $\begin{array}{r}\text { Average \% } \\
\text { information } \\
\text { per RE }\end{array}$ & $\begin{array}{r}\text { Average \% } \\
\text { information } \\
\text { per NRE }\end{array}$ \\
\hline Gender & .16 & .11 & -.11 & .02 & -.05 & .05 & -.05 & .03 & -.05 \\
\hline Education & & -.06 & .03 & .12 & -.01 & .14 & -.14 & -.02 & -.06 \\
\hline Political orient. & & & .11 & $-.27 * *$ & $.41 * *$ & $-.32 * *$ & $.32 * *$ & -.09 & $-.31 *$ \\
\hline Age & & & & -.13 & .07 & -.08 & .08 & $-.22 *$ & -.13 \\
\hline Affect RE & & & & & -.10 & $.40 * *$ & $-.40 * *$ & $.32 * *$ & -.03 \\
\hline Affect NRE & & & & & & $-.39 * *$ & $.39 * *$ & $.27 *$ & -.08 \\
\hline Proportion RE & & & & & & & $-1.00 * *$ & -.04 & .08 \\
\hline $\begin{array}{r}\text { Proportion } \\
\text { NRE }\end{array}$ & & & & & & & & .04 & -.08 \\
\hline $\begin{array}{r}\text { Average \% } \\
\text { Information RE }\end{array}$ & & & & & & & & & -.18 \\
\hline
\end{tabular}




\subsection{Predictors of information searched regarding $\mathrm{RE}$ technologies}

We ran a two-step hierarchical regression analysis between the average amount of information regarding renewable electricity technologies that was considered by participants (average \% information RE) and a set of explanatory factors. We included the socio-demographic variables of gender, age, education, and political orientation in step 1, while we added affect toward RE and affect toward NRE in step 2.

We were interested to discover whether age, affect toward RE, and affect toward NRE are independent predictors of the percentage of information attended to regarding RE when controlling for the other socio-demographic variables. In Table 3, it can be seen that the socio-demographic variables, as entered in Model 1, did not predict how much information was attended to regarding RE, resulting in a model that was non-significant overall . However, when both the affect toward RE and the affect toward NRE were added in Model 2, both turned out to be independent predictors, thereby resulting in a model that was significant overall (see Table 3).

Table 3

Hierarchical regression on the \% information attended to, on average, per renewable energy technology

Average \% information per renewable (RE)

\begin{tabular}{lllll}
\multicolumn{5}{c}{ Average \% information per renewable (RE) } \\
\hline & Model 1 & \multicolumn{3}{l}{ Model 2 } \\
\hline Constant & $\mathrm{B}(\mathrm{SE})$ & $\beta$ & $\mathrm{B}(\mathrm{SE})$ & $\beta$ \\
Gender & $.18(.04)$ & $* * *$ & $.01(.06)$ & \\
Age & $-.002(.02)$ & .02 & $.01(.01)$ & .06 \\
Education & $-.001(.001)$ & -.21 & $-.001(.001)$ & -.18 \\
Political orientation & $-.001(.01)$ & -.02 & $-.003(.004)$ & -.07 \\
Affect RE & $-.002(.004)$ & -.07 & $-.01(.004)$ & -15 \\
Affect NRE & & & $.002(.001)$ & $.30^{* *}$ \\
& & & $.002(.00)$ & $.37^{* * *}$ \\
$R 2$ & & .05 & & .25 \\
$F$ & & 1.08 & & $4.32^{* * *}$ \\
$\Delta R^{2}$ & & & & .20 \\
$\Delta F$ & & & & $10.30^{* * *}$ \\
\hline
\end{tabular}

Note. $\mathrm{N}=85, * \mathrm{p}<.05, * * \mathrm{p}<.01, * * * \mathrm{p}<.001$ 


\subsection{Predicting the proportion of RE technologies in a portfolio}

In addition, we investigated the relationship between the proportion of RE in the portfolio and a set of explanatory factors using a three-step hierarchical regression analysis. In step 1, the socio-demographic variables, namely gender, age, education, and political orientation, were included as predictors. In step 2, the affect toward RE as well as the affect toward NRE were added. In step 3, we added the variables intended to measure how much information was attended to, on average, for renewable energy technologies (average \% information RE) and non-renewable technologies (average \% information NRE).

During the first step of the hierarchical regression, political orientation was the only significant predictor of the proportion of RE in the portfolio, with being oriented toward the right found to be associated with a lower proportion of RE. When the affect toward RE and the affect toward NRE were added to the regression model, however, political orientation became non-significant (Table 4, Model 2). Affect hence seemed to mediate the relationship between political orientation and the proportion of $\mathrm{RE}$ in the portfolio.

In Model 2, more positive affect toward RE was found to be related to more RE in the portfolio, while more positive affect toward NRE was related to a smaller proportion of RE in the portfolio. The addition of the affect-related predictor variables also improved the variance explained by the model from $11 \%$ to $29 \%$. In contrast, the average percentage of information attended to regarding RE or NRE did not improve the model fit (see Table 4, Model 3). 
Table 4

Hierarchical regression on the proportion of renewable energy in the portfolio

\begin{tabular}{|c|c|c|c|c|c|c|}
\hline \multicolumn{7}{|c|}{ Proportion of renewables (RE) } \\
\hline & Model 1 & & Model 2 & & Model 3 & \\
\hline & $\mathrm{B}(\mathrm{SE})$ & $\beta$ & $\mathrm{B}(\mathrm{SE})$ & $\beta$ & $\mathrm{B}(\mathrm{SE})$ & $\beta$ \\
\hline Constant & $91.85(6.42)$ & $* * *$ & $69.45(9.67)$ & $* * *$ & $68.4(10.12)$ & $* * *$ \\
\hline Gender & $1.49(2.42)$ & .07 & $.90(2.20)$ & .04 & $1.04(2.23)$ & .05 \\
\hline Age & $-.03(.09)$ & -.04 & $.004(.08)$ & .01 & $-.01(.08)$ & -.01 \\
\hline Education & $.73(.72)$ & .11 & $.56(.65)$ & .08 & $.54(.66)$ & .08 \\
\hline Political orientation & $-1.89(.64)$ & $-.32 * *$ & $-.62(.65)$ & -.10 & $-.62(.69)$ & -.10 \\
\hline Affect RE & & & $.32(.10)$ & $.33 * * *$ & $.35(.10)$ & $.36 * * *$ \\
\hline Affect NRE & & & $-.21(.07)$ & $-.31 * *$ & $-.19(.08)$ & $-.28 *$ \\
\hline Average \% Information RE & & & & & $-14.43(17.78)$ & -.09 \\
\hline Average \% Information NRE & & & & & $7.49(19.54)$ & .04 \\
\hline$R 2$ & & .12 & & .30 & & .31 \\
\hline$F$ & & $2.81 *$ & & $5.53 * * *$ & & $4.17 * * *$ \\
\hline$\Delta R^{2}$ & & & & .18 & & .01 \\
\hline$\Delta F$ & & & & $9.74 * * *$ & & 0.36 \\
\hline
\end{tabular}


We also conducted a mediation analysis in order to test the effect of political orientation on the proportion of renewables in a portfolio, using the affect toward RE and the affect toward NRE as two mediators. We assumed that the two mediators would not influence each other, since the bivariate correlation was low and non-significant (see Table 2). We used bias-corrected 95\% bootstrap confidence intervals based on 5000 bootstrap samples to estimate the indirect effect of political orientation on the proportion of RE, which was below zero (-3.16 to -0.63). Political orientation had a direct effect on the affect experienced toward RE and the affect experienced toward NRE, which, in turn, both had an effect on the proportion of renewable energy technologies included in the portfolio. Consequently, there was a complete parallel mediation of the effect of political orientation on the proportion of renewables included in the portfolio (Figure 3).

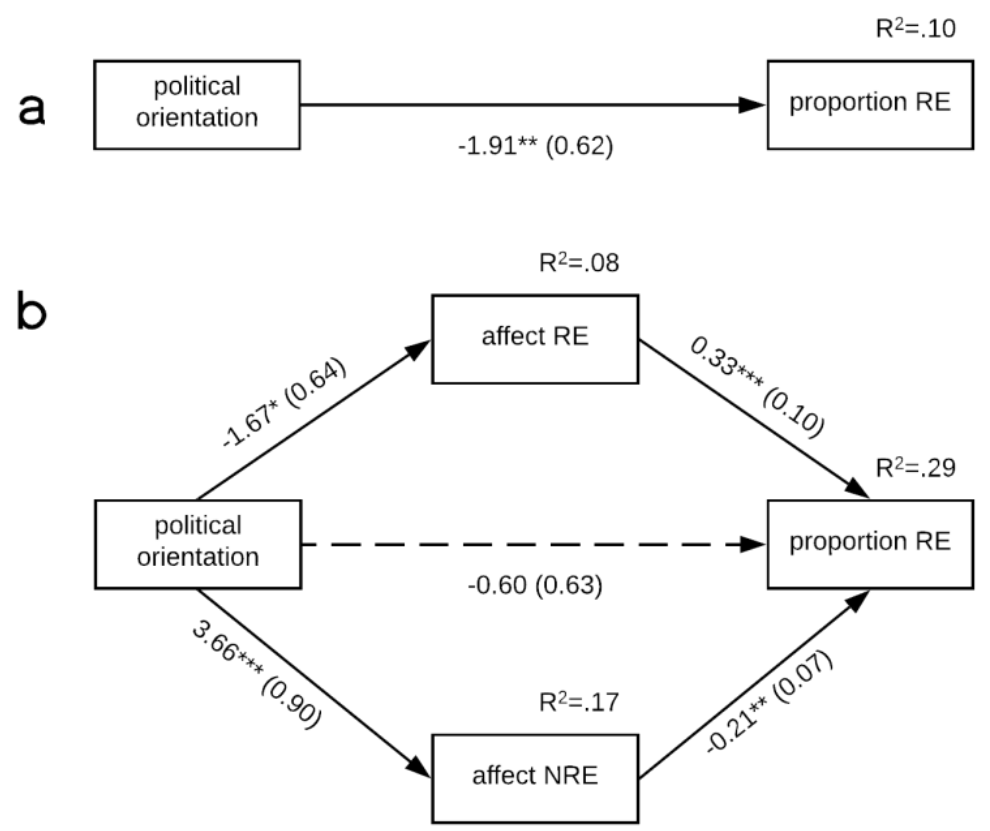

Figure 3. Results of the mediation analysis for the proportion of renewable energy technologies included in the portfolio: a) shows the total effect of political orientation on the proportion of RE, while b) shows the parallel mediation with the affect toward RE and the affect toward NRE. The non-standardized coefficients (SEs) are reported. Dashed lines display paths that are non-significant.

\section{Discussion}

We found that participants' political orientation and the affective reactions experienced toward energy technologies guided their information search when using a decision support tool. Hence, prior attitudes and beliefs guided how participants engaged with the present DSS. Yet, we did not find that the 
information processed was related to the portfolio choice, in the sense that the proportion of renewable energy technologies included within the portfolio did not exhibit a direct relationship with the attention paid to information. However, both the affect toward RE and the affect toward NRE mediated the effect of political orientation on the choice of renewables included in a portfolio. Hence, prior attitudes not only influenced what information was searched for, but also the type of portfolio the participants considered to be best for the future Swiss electricity system.

The present study was able to shed more light on how people engage with a DSS that provides information concerning the electricity system in an interactive format. We found that, on average, our participants attended to more information about renewable than non-renewable energy technologies. The attention paid to information was driven by different factors for both types of energy technologies. While political orientation was related to how much information was searched regarding nonrenewables, the affect associated with energy technologies seemed to drive the amount of information attended to regarding renewable energy technologies.

These findings provide further evidence that information is viewed through the lens of the previous attitudes and beliefs that people hold. Information is often selectively processed by people leading to a one-sided exposure to information that is congruent with previously held attitudes and beliefs (Taber, Cann, \& Kucsova, 2008). Additionally, people also tend to disconfirm information that they do not agree with (Taber et al., 2008). Generally, distrust in information is more pronounced in more conservative people (Kraft, Suhay, Druckman, Lodge, \& Taber, 2015). Such people are more inclined to question the added value of scientific information when compared to more liberal individuals, and they show greater avoidance of new empirical data (Tullett, Hart, Feinberg, Fetterman, \& Gottlieb, 2016). On the contrary, liberals exhibit a greater need for cognition, more frequently engaging in more deliberate thinking when compared to conservatives (Jost, 2017).

We observed this pattern in our study regarding the information search concerning non-renewable energy technologies. Participants who reported right-leaning political orientations looked up less 
information regarding these technologies, which also meant that participants oriented more toward the left attended to more information. However, we could not confirm this pattern for the attention paid to information regarding renewable energy technologies. Instead of the participants' political orientation, a more positive affect toward renewables and a more positive affect toward non-renewables drove their information search. Affect has been related to information searching in previous research, wherein very positive affect (but also very negative affect) toward vaccines was found to drive the information search concerning that topic (Allen Catellier \& Yang, 2012). This type of information processing could be employed in order to maintain positive feelings when initial positive affect is experienced. It could, however, also represent a means of managing negative attitudes and finding supporting information for such attitudes, as Allen Catellier and Yang (2012) suggest. In terms of our findings, this argumentation implies that positive affective reactions toward non-renewable energy technologies could be related to a more extensive information search regarding renewables that was engaged in to confirm pre-existing beliefs about the negative consequences of renewables, or that non-renewables represent better alternatives when compared to renewable technologies. This suggest that people who have a positive attitude towards non-renewables might be looking for negative information on renewable technologies. Decision aids have previously been shown to assist individuals in focusing on the information most important to them (Bansback et al., 2014). We contend that this is also reflected in DSSs that provide information through an interactive interface, as was the case in the present study. Indeed, people defined their own information search, and they used the searched information to confirm their prior attitudes and beliefs rather than to find evidence countering what they believed.

This type of information processing within a DSS is challenging, since selective information processing coupled with disconfirmation bias, meaning that information incongruent with previous beliefs is disregarded as wrong or untrustworthy, can lead to confirmation bias and the subsequent polarization of attitudes (Taber et al., 2008). Thus, if the goal of a DSS is to inform the public and find better common ground for, for example, the implementation of the energy transition in a given country, the provision of information through a DSS could potentially backfire. However, not all users might be prone to the effects of selective information processing, confirmation bias, and polarization. Being more 
curious about science (Kahan, Landrum, Carpenter, Helft, \& Hall Jamieson, 2017), or having a greater need for accurate information (Hart et al., 2009), and also holding weaker prior beliefs and attitudes, are related to less biased information processing (Taber et al., 2008).

The attention paid to information concerning renewable and non-renewable technologies was not directly related to the choice of an energy technology portfolio. In a DSS that focused on providing interactive information, people seemed to rely on the more automatic and intuitive processes of the experiential system in order to simplify their decision-making process (Tversky \& Kahneman, 1974). We thus found strong evidence that the participants used affective reactions as orienting mechanisms (Finucane, Alhakami, Slovic, \& Johnson, 2000) when choosing an energy portfolio, even if they could have relied on objective information.

Does this imply that information is meaningless in terms of helping people with their decision making? In prior studies, self-reported motivation to actively gather information on energy services was low (Chapman \& Itaoka, 2018) and reading and discussing information concerning the consequences of energy technologies barely changed people's preferences with regard to their energy portfolio (Mayer et al., 2014), while their affective reactions toward the different technologies were strongly related before and after they read educational material (Bruine de Bruin \& Wong-Parodi, 2014). We argue that while affective evaluations of energy technologies represent a driving force behind portfolio choice, the processed information could potentially have influenced people's choice, considering that the effects of different types of information could have cancelled each other out. For example, we could assume that information regarding the generation of waste during the production of solar panels would be related to a decrease in the proportion of solar power within the portfolio, which is analogous to the findings of Sütterlin and Siegrist (2017). However, information concerning the relatively low $\mathrm{CO}_{2}$ emissions associated with solar power could, in contrast, have led to an increase in the proportion of solar power within the portfolio, if that information was considered to represent a benefit by the participants. 
As different information was provided simultaneously, we could not disentangle the respective effects in the current analysis. In previous research, information concerning negative consequences was found to induce negative moods, which, in turn, led people to judge the associated risks to be higher (Johnson \& Tversky, 1983). Higher perceived risks then decreased the acceptance of technologies (Visschers \& Siegrist, 2014). In sum, information can influence people's affective evaluations, which are, in turn, predictive of the acceptance or choice of energy technologies. As has in part been done by Sütterlin and Siegrist (2017) for the acceptance of solar, wind and hydropower, separate investigations of the effects of different types of information on the affective evaluations of energy technologies and, in turn, portfolio choice or acceptance appear necessary in future research in order to assess the importance of different impacts (e.g., air pollution, health impacts, or price) on people's portfolio preferences.

A question remains concerning whether people can be encouraged to choose more renewable energy technologies for their portfolios, so as to expand the common ground for the implementation of the current Swiss energy strategy. As political orientation and affect are both fundamental determinants of people's choices and behaviors, as reflected in our findings, achieving change appears to be challenging. One potential avenue might be to diminish the affective component of a choice. When the names of the technologies were blinded for a choice between different portfolios, the participants focused more on the impacts these portfolios would have, and they were less guided by the types of technologies that were included in the portfolios (Bessette et al., 2016). Yet, blinding the names of technologies is not widely applicable in public discourse. A weaker relationship between affect and choice was, however, also observed for DSSs that, in addition to providing information, facilitated the user's engagement with that information during the decision-making process by decomposing the decision task into more manageable pieces (Arvai \& Gregory, 2003; Bessette et al., 2014; Bessette et al., 2016).

A second possibility is to motivate people to seek information that is incongruent with their prior beliefs when they pursue another goal, for example, to debate the issue afterwards and, therefore, to determine possible counter-arguments to their existing preferences or beliefs (Hart et al., 2009). A third potential strategy could be to activate people's curiosity regarding science and facts, which has previously been suggested to decrease potential biases in terms of information processing (Kahan et al., 2017). 
It is important to note that the current study, as with any study, faces certain limitations. First, the investigated sample size is rather small. However, as we conducted the study in a laboratory setting, we were able to ensure that the participants used the DSS and did not look up information on the Internet when making their choices. Hence, we favored a more controlled study setting so as to ensure the validity of the results.

Second, we did not measure participants' trust in the institution that provided the information. This is, however, a relevant dimension in relation to information searching. Allen Catellier and Yang (2012) found that people who exhibited a higher level of trust had a higher likelihood of seeking information when their affect toward a given object was positive. Hence, trust in the information provided using a DSS and positive affect toward energy technologies could interact and might even be a reason why some people process more information than others in such decision-making environments, although we note that trust in scientists and governmental institutions is high in Switzerland (Visschers et al., 2011).

\section{Conclusion}

We investigated how the Swiss public engages with a DSS that provides interactive information when asked to choose the electricity mix that they preferred to see implemented in the future. The findings show that people's political orientation, as well as their affective reactions to energy technologies, guide both their information search and the choice of energy technologies within their portfolio. While this could be an indication that people are able to target information that they value or are familiar with, it also implies that people only expose themselves to a specific selection of information. This points to selective information processing, which can lead to confirmation bias if information that contradicts previous attitudes and beliefs is discounted. Based on previous research concerning motivated political reasoning, this could even lead to the further polarization of attitudes. Additionally, the attention paid to information concerning renewable energy technologies was not directly related to a higher proportion of renewables being included in portfolios. The provision of information through an interactive interface, as in the case of the present DSS, hence seems unable to change the affective-cognitive evaluation of energy technologies. The use of interactive interfaces should be carefully considered in light of the possible effects of consolidating existing beliefs. 


\section{References}

Allen Catellier, J. R., \& Yang, Z. J. (2012). Trust and affect: how do they impact risk information seeking in a health context? Journal of Risk Research, 15(8), 897-911. doi:10.1080/13669877.2012.686048

Ansolabehere, S., \& Konisky, D. M. (2014). Cheap and clean. How America thinks about energy in the age of global warming. Cambridge, London: The MIT Press.

Arvai, J., \& Gregory, R. (2003). Testing Alternative Decision Approaches for Identifying Cleanup Priorities at Contaminated Sites. Environmental Science \& Technology, 37(8), 1469-1476.

Arvai, J., Kellon, D., León, R., Gregory, R., \& Richardson, R. (2014). Structuring international development decisions: confronting trade-offs between land use and community development in Costa Rica. Environment Systems and Decisions, 34(2), 224-236. doi:10.1007/s10669-0149495-4

Assouline, D., Mohajeri, N., \& Scartezzini, J.-L. (2017). Quantifying rooftop photovoltaic solar energy potential: A machine learning approach. Solar Energy, 141, 278-296. doi:10.1016/j.solener.2016.11.045

Bansback, N., Li, L. C., Lynd, L., \& Bryan, S. (2014). Development and preliminary user testing of the DCIDA (Dynamic computer interactive decision application) for 'nudging' patients towards high quality decisions. BMC Medical Informatics and Decision Making, 14, 62-62. doi:10.1186/1472-6947-14-62

Bergmann, A., Hanley, N., \& Wright, R. (2006). Valuing the attributes of renewable energy investments. Energy Policy, 34(9), 1004-1014. doi:10.1016/j.enpol.2004.08.035

Bessette, D. L., \& Arvai, J. (2018). Engaging attribute tradeoffs in clean energy portfolio development. Energy Policy, 115, 221-229. doi:10.1016/j.enpol.2018.01.021

Bessette, D. L., Arvai, J., \& Campbell-Arvai, V. (2014). Decision support framework for developing regional energy strategies. Environmental Science \& Technology, 48(3), 1401-1408. doi:10.1021/es4036286

Bessette, D. L., Campbell-Arvai, V., \& Arvai, J. (2016). Expanding the reach of participatory risk management: Testing an online decision-aiding framework for informing internally consistent choices. Risk Analysis, 36(5), 992-1005. doi:10.1111/risa.12481

Blumer, Y. B., Moser, C., Patt, A., \& Seidl, R. (2015). The precarious consensus on the importance of energy security: Contrasting views between Swiss energy users and experts. Renewable and Sustainable Energy Reviews, 52, 927-936. doi:10.1016/j.rser.2015.07.081

Breyer, B. (2015). Left-Right self-placement scale (ALLBUS / GGSS). The collection items and scales for the Social Sciences. Retrieved from https://zis.gesis.org/skala/Breyer-Left-Right-SelfPlacement-(ALLBUS) [Accessed September 2, 2017].

Bruine de Bruin, W., \& Wong-Parodi, G. (2014). The role of initial affective impressions in responses to educational communications: the case of carbon capture and sequestration (CCS). Journal of Experimental Psychology: Applied, 20(2), 126-135. doi:10.1037/xap0000008

Chapman, A., \& Itaoka, K. (2018). Curiosity, economic and environmental reasoning: Public perceptions of liberalization and renewable energy transition in Japan. Energy Research \& Social Science, 37, 102-110. doi:10.1016/j.erss.2017.09.026

Corner, A., Venables, D., Spence, A., Poortinga, W., Demski, C., \& Pidgeon, N. (2011). Nuclear power, climate change and energy security: Exploring British public attitudes. Energy Policy, 39(9), 4823-4833. doi:10.1016/j.enpol.2011.06.037

Federal Statistical Office (FSO). (2017a). Bildungsstand der Wohnbevölkerung nach Alter und Geschlecht, 1999-2016 [Education level of the resident population according to age and gender, 1999 - 2016] Bern: Federal Statistical Office Retrieved from https://www.bfs.admin.ch/bfs/de/home/statistiken/bildung-wissenschaft/bildungsstandkompetenzen/bevoelkerung.assetdetail.2662056.html [Accessed September 5, 2017].

Federal Statistical Office (FSO). (2017b). Ständige Wohnbevölkerung nach Alter, Geschlecht und Staatsangehörigkeitskategorie, 2010-2016. [Resident population according to age, gender and category of citizenship]. Bern: Federal Statistical Office Retrieved from https://www.bfs.admin.ch/asset/de/je-d-01.02.03.02 [Accessed September 5, 2017]. 
Finucane, M., Alhakami, A., Slovic, P., \& Johnson, S. M. (2000). The affect heuristic in judgments of risks and benefits. Journal of Behavioral Decision Making, 13, 1 - 17.

Hart, W., Albarracin, D., Eagly, A. H., Brechan, I., Lindberg, M. J., \& Merrill, L. (2009). Feeling validated versus being correct: a meta-analysis of selective exposure to information. Psychological Bulletin, 135(4), 555-588. doi:10.1037/a0015701

Howarth, C. (2017). Informing decision making on climate change and low carbon futures: Framing narratives around the United Kingdom's fifth carbon budget. Energy Research \& Social Science, 31, 295-302. doi:10.1016/j.erss.2017.06.011

Hsee, C. K. (1996). The evaluability hypothesis: An explanation for preference reversals between joint and separate evaluations of alternatives. Organizational Behavior and Human Decision Processes, 67(3), 247-257.

International Energy Agency (IEA). (2017). World energy outlook 2017. Global shifts in the energy system. Retrieved from https://www.iea.org/weo2017/ [Accessed April 4, 2018]

Jobin, M., \& Siegrist, M. (2018). We choose what we like - Affect as a driver of electricity portfolio choice. Energy Policy, 122, 736-747. doi:10.1016/j.enpol.2018.08.027

Johnson, E. J., \& Tversky, A. (1983). Affect, generalization, and the perception of risk. Journal of Personality and Social Psychology, 45(1), 20-31.

Jost, J. T. (2017). The marketplace of ideology: "Elective affinities" in political psychology and their implications for consumer behavior. Journal of Consumer Psychology, 27(4), 502-520. doi:10.1016/j.jcps.2017.07.003

Kahan, D. M., Landrum, A., Carpenter, K., Helft, L., \& Hall Jamieson, K. (2017). Science curiosity and political information processing. Political Psychology, 38, 179-199. doi:10.1111/pops. 12396

Kienast, F., Huber, N., Hergert, R., Bolliger, J., Moran, L. S., \& Hersperger, A. M. (2017). Conflicts between decentralized renewable electricity production and landscape services - A spatiallyexplicit quantitative assessment for Switzerland. Renewable and Sustainable Energy Reviews, 67, 397-407. doi:10.1016/j.rser.2016.09.045

Kraft, P. W., Suhay, E., Druckman, J. N., Lodge, M., \& Taber, C. S. (2015). Why people "Don't Trust the Evidence". The ANNALS of the American Academy of Political and Social Science, 658(1), 121-133. doi:10.1177/0002716214554758

Lienert, P., Sütterlin, B., \& Siegrist, M. (2017). The influence of high-voltage power lines on the feelings evoked by different Swiss surroundings. Energy Research \& Social Science, 23, 4659. doi:10.1016/j.erss.2016.11.010

Markard, J., Suter, M., \& Ingold, K. (2016). Socio-technical transitions and policy change - Advocacy coalitions in Swiss energy policy. Environmental Innovation and Societal Transitions, 18, 215237. doi:10.1016/j.eist.2015.05.003

Mayer, L. A., Bruine de Bruin, W., \& Morgan, M. G. (2014). Informed public choices for low-carbon electricity portfolios using a computer decision tool. Environmental Science \& Technology, 48(7), 3640-3648. doi:10.1021/es403473x

Morgan, M. G., Fischhoff, B., Bostrom, A., \& Atman, C. J. (2002). Risk communication a mental models approach. Cambridge: Cambridge University Press.

Panos, E., \& Kannan, R. (2016). The role of domestic biomass in electricity, heat and grid balancing markets in Switzerland. Energy, 112, 1120-1138. doi:10.1016/j.energy.2016.06.107

Pidgeon, N. F., Demski, C., Butler, C., Parkhill, K., \& Spence, A. (2014). Creating a national citizen engagement process for energy policy. Proceedings of the National Academy of Sciences of the United States of America, 111 (Supplement 4), 13606-13613. doi:10.1073/pnas.1317512111

Questback Ltd. (2015). Unipark [Computer software]. Köln.

Rudolf, M., Seidl, R., Moser, C., Krütli, P., \& Stauffacher, M. (2014). Public preference of electricity options before and after Fukushima. Journal of Integrative Environmental Sciences, 11(1), 115. doi:10.1080/1943815x.2014.881887

Schulte-Mecklenbeck, M., Kühberger, A., Gagl, B., \& Hutzler, F. (2017). Inducing thought processes: Bringing process measures and cognitive processes closer together. Journal of Behavioral Decision Making. 
Schulte-Mecklenbeck, M., Kühberger, A., \& Ranyard, R. (2011). The role of process data in the development and testing of process models of judgment and decision making. Judgment and Decision Making, 6(8), 733-739.

Seidman, I. (1998). Interviewing as qualitative research a guide for researchers in education and the social sciences (2nd ed.). New York: Teachers College Press.

Stern, P. C., Sovacool, B. K., \& Dietz, T. (2016). Towards a science of climate and energy choices. Nature Climate Change, 6(6), 547-555. doi:10.1038/nclimate3027

Stokes, L. C., \& Warshaw, C. (2017). Renewable energy policy design and framing influence public support in the United States. Nature Energy, 2(8), 17107. doi:10.1038/nenergy.2017.107

Sütterlin, B., \& Siegrist, M. (2017). Public acceptance of renewable energy technologies from an abstract versus concrete perspective and the positive imagery of solar power. Energy Policy, 106, 356-366. doi:10.1016/j.enpol.2017.03.061

Swiss Federal Office of Energy (SFOE). (2012). Wasserkraftpotenzial der Schweiz [Hydropower potential in Switzerland]. Ittigen: Swiss Federal Office of Energy.

Swiss Federal Office of Energy (SFOE). (2013a). Botschaft zum ersten Massnahmenpaket der Energiestrategie 2050 (Revision des Energierechts) und zur Volksinitative "Für den geordneten Ausstieg aus der Atomenergie (Ausstiegsinitiative)"[Dispatch concerning the first set of measures of the energy strategy 2050 (revision of the energy law) and the popular petition "for the orderly phasing-out of nuclear power"]. Ittigen: Swiss Federal Office of Energy.

Swiss Federal Office of Energy (SFOE). (2013b). Energieperspektiven 2050 - Zusammenfassung [Energy scenarios 2050 - summary]. Ittigen: Swiss Federal Office of Energy.

Swiss Federal Office of Energy (SFOE). (2016). Schweizerische Elektrizitätsstatistik [Swiss Electricity statistic]. Ittigen: Swiss Federal Office of Energy.

Swiss Federal Office of Energy (SFOE). (2017). Wichtigste Neuerungen im Energierecht ab 2018 [Main alterations in the Energy law starting 2018]. Ittigen: Swiss Federal Office of Energy.

Taber, C. S., Cann, D., \& Kucsova, S. (2008). The motivated processing of political arguments. Political Behavior, 31(2), 137-155. doi:10.1007/s11109-008-9075-8

Tabi, A., \& Wüstenhagen, R. (2017). Keep it local and fish-friendly: Social acceptance of hydropower projects in Switzerland. Renewable \& Sustainable Energy Reviews, 68, 763-773. doi:10.1016/j.rser.2016.10.006

Truelove, H. B. (2012). Energy source perceptions and policy support: Image associations, emotional evaluations, and cognitive beliefs. Energy Policy, 45, 478-489. doi:10.1016/j.enpol.2012.02.059

Tullett, A. M., Hart, W. P., Feinberg, M., Fetterman, Z. J., \& Gottlieb, S. (2016). Is ideology the enemy of inquiry? Examining the link between political orientation and lack of interest in novel data. Journal of Research in Personality, 63, 123-132. doi:10.1016/j.jrp.2016.06.018

Tversky, A., \& Kahneman, D. (1974). Judgment under uncertainty: Heuristics and biases. Science, 185, 1124-1131.

van Buul, V. J., Bolman, C. A. W., Brouns, F., \& Lechner, L. (2017). Back-of-pack information in substitutive food choices: A process-tracking study in participants intending to eat healthy. Appetite, 116, 173-183. doi:10.1016/j.appet.2017.04.036

Visschers, V. H. M., Keller, C., \& Siegrist, M. (2011). Climate change benefits and energy supply benefits as determinants of acceptance of nuclear power stations: Investigating an explanatory model. Energy Policy, 39(6), 3621-3629. doi:10.1016/j.enpol.2011.03.064

Visschers, V. H. M., \& Siegrist, M. (2014). Find the differences and the similarities: Relating perceived benefits, perceived costs and protected values to acceptance of five energy technologies. Journal of Environmental Psychology, 40, 117-130. doi:10.1016/j.jenvp.2014.05.007

Wilson, R., \& Arvai, J. (2006). When less is more: How affect influences preferences when comparing low and high-risk options. Journal of Risk Research, 9(2), 165-178. doi: $10.1080 / 13669870500419503$

Zikmund-Fisher, B. J., Dickson, M., \& Witteman, H. O. (2011). Cool but counterproductive: interactive, Web-based risk communications can backfire. Journal of Medical Internet Research, 13(3), e60. doi:10.2196/jmir.1665 
